МЕХАНИЗМЫ ВЛИЯНИЯ ОПИОДНЫХ АНАЛЬГЕТИКОВ НА ОСОБЕННОСТИ РЕАКЦИИ ЭНДОГЕННОЙ ОПИАТНОЙ СИСТЕМЫ ОРГАНИЗМА И РЕГУЛЯЦИЮ СОКРАТИТЕЛЬНОЙ АКТИВНОСТИ МАТКИ ПРИ НОЦИЦЕПТИВНОМ ОТВЕТЕ В ЭКСПЕРИМЕНТЕ НА КРЫСАХ В МОДЕЛИ ИНДУЦИРОВАННОЙ РОДОВОЙ БОЛИ

\author{
(C) А.Г. Киселев ${ }^{1}$, А. А. Зайцев ${ }^{2}$ \\ ${ }^{1}$ ФГБНУ «НИИ АГиР им. Д. О. Отта», Санкт-Петербург; \\ ${ }^{2}$ НИИ фармакологии им. Вальдмана, Санкт-Петербург
}

\begin{abstract}
- Представлены результаты экспериментального исследования действия опиоидных анальгетиков на ноцицептивные реакции гемодинамики, дыхания и тонус скелетной мускулатуры крыс. Показано влияние аналгезии опиатами на показатели амплитуды и частоты сокращений миометрия у небеременных и беременных крыс. Изучены фармакологические эффекты опиоидов в условиях беременности и при модели болевой реакции в родах.
\end{abstract}

ш Ключевые слова: опиатные аналгетики; ноцицептивные реакции; дыхание; кровообращение; сократительная активность матки.

\title{
OPIOID ANALGESICS EFFECTS MECHANISMS ON THE PARTICULAR REACTION OF ENDOGENOUS OPIOID SYSTEM OF THE BODY AND THE REGULATION OF UTERINE ACTIVITY DURING THE NOCICEPTIVE RESPONSE IN THE EXPERIMENT ON RATS
}

\author{
(C) A. G. Kiselev ${ }^{1}$, A. A. Zaitsev ${ }^{2}$ \\ ${ }^{1}$ D. O. Ott Research Institute for Obstetrics and Gynecology, Saint Petersburg, Russia; \\ ${ }^{2}$ Waldman Research Institute of Pharmacology, Saint Petersburg, Russia
}

- This article presents the results of experimental investigation of opioid (opiate analgesics) influence on the nociceptive response of rat's circulatory dynamics, breath and skeletal muscles tonus. The article demonstrates influence of opiate analgesics on intact and pregnant rat's amplitude and frequency of uterine activity. The results of investigation of drug-induced effect of opiate analgesics in case of pregnant and in case of act of delivery model pain reaction were also described in this article.

- Key words: opiate analgetics; nociceptive response; breath; blood circulation; uterine activity.

\section{Введение}

Одним из важных направлений в современной акушерской анестезиологии является выбор медикаментозных препаратов наиболее близких к собственной противоболевой (эндорфинной) системе. К таким препаратам относятся опиоиды. Однако механизмы влияния опиатов и опиоидов на сократительную способность матки практически не изучены. Так же во многом не определены механизмы влияния эндорфинов в сократительную активность матки. Ранее нами исследовалось влияние опиоидов на импульсную секрецию окситоцина и изменение уровня эндорфинов в родах $[20,21]$ хотя из-за различия применяемых методик полученные данные трактовать однозначно трудно. С уверенностью можно лишь сказать, что значения опиоидэргического звена антиноцицептивной системы и эндорфинная регуляция процесса родов несомненны. Изучение влияния обезболивания опиатными анальгетиками на характер ноцицептивных реак- ций и сократительную активность матки в родах до настоящего времени остается актуальным, но до конца не изученной проблемой. Не оценена реальная польза применения опиатов при устранении боли на систему дыхания, кровообращение, мышечный тонус, болевое поведение, седацию и миоплегию. Экспериментальное изучение на животных этих аспектов обезболивания родов позволяют по-новому взглянуть на необходимость обезболивания родов у человека, оценить значимость опиатного звена антиноцецептивной защиты организма. Важным в эксперименте является возможность оценить наличие прямого влияния опиодных аналгетиков на сократительную способность беременной матки, которое по нашим предварительным данным реализуется через ионные каналы. В родах, которые у человека сопровождаются болью на каждое мышечное сокращение, то есть схватку, особо важным является разделение антиноцицептивного ответа и опосредованного влияния опиоидов через из- 
менение функции дыхания и кровообращения при обезболивающем действии опиатов на сократительтую активность рожающей матки, то есть общего обезболивания и прямого регулирующего интенсивность сокращений миометрия и обезболивающего действия опиодов на уровне гладкой мускулатуры матки. Эсперементальное изучение этих механизмов требует создания на животных модели родов сходных с болевыми ощущениями сопровождающими роды у человека.

На наш взгляд актуальным и научно значимым в исследовании является определение роли опиатных анальгетиков при обезболивании родов, когда помимо болеутоления реализуются механизмы регуляции родовой деятельности, по-видимому, запрограммированные генетически и тесно связанные с опиоидэргической составляющей антиноцицептивной системы организма женщины. С другой стороны, ответ организма на боль создает ряд условий для реализации эффективного раскрытия шейки матки через гемодинамические механизмы функциональной перестройки шейки матки, гистологической структуры маточного зева и нижнего сегмента матки, создания правильного ритма сократительной деятельности матки человека приводящие, в конечном результате, к успешной реализации биологического механизма родов у человека. Неполноценность эндогенной опиатной системы женщины, по-видимому, лежит в основе развития аномалий родовой деятельности, так как полезные гемодинамические реакции ответа на боль не реализуются, да и чрезмерное болевое ощущение нарушает механизмы нормальной сократительной деятельности матки. Нами в процессе исследования в эксперименте на беременных и небеременных самках крыс удалось смоделировать эффективность болеутоляющего действия опиодных анальгетиков, показав их направленное действие на систему гемодинамики в аспекте антиноцицептивного воздействия и прямое действие на маточные сокращения индуцированные электическими сигналами или окситоцином.

\section{Материал и методы исследования}

Исследование было проведено на 320 инбредных крысах линии Вистар. Изучение ноцицептивной реакции включало определение данных по латентному периоду отдергивания хвоста, порога вокализации, измерению артериального давления и его прессорных сдвигов, частоты дыхания, определение эмоциональной реактивности в реакции на звонок, измерение тонуса скелетной мускулатуры в тесте удержания на стержне, измерение биопотенциалов миометрия при регистрации спонтанной активности, электростимулирующем и окситоциновом воздействии. Контроль был сформирован из группы небеременных и беременных крыс при сроке беременности 20 дней. Каждая из групп состояла из 22 животных. Остальные животные были рандомизированы в 7 групп. Группа с промедолом 48 животных по 12 с дозой препарата 2,7 , 14, 21 мг, группа фентанила 40 крыс по 10 с каждой дозой препарата $0,03,0,07,0,14,0,2$ мг группа трамадола 44 по 11 с каждой дозой препарата 35 , 70, 140 мг, 200 мг группа, дипидоллора 40 крыс по 10 с каждой дозой препарата $3,8,7,5,1,5$, 3,0 мг соответственно, группа морадола 44 животных по 11 в группе $0,1,0,2,0,4,0,5$ мг, группа налоксона 20 по 10 соответственно $0,05,0,1,0,2$, 0,3 мг. Всего 150 особей беременных и столько же небеременных. Дополнительную группу по изучению сократительной деятельности матки составили 20 животных (из них 10 беременных), которым вводили антагонисты кальциевых каналов на примере веропамила 1 мг, 3 мг.

Болеутоляющее действие фармакологических средств оценивали в альтернативной форме при термическом и электрическом ноцицептивном воздействиях с помощью традиционных скрининговых тестов [4]. Тест боли термической природы состоял в оценке скорости и интенсивности реакции одергивания хвоста (tail-flick).Тест производили при раздражении проксимальной трети хвоста крыс сфокусированным через увеличительное стекло пучком света от лампы накаливания. Лампа выключалась автоматически при отдергивании хвоста, длительность температурного воздействия в этот момент (т. е. латентный период отдергивания хвоста) фиксировалась электронным секундомером в секундах.

Аналгезию при боли «электрической» природы определяли по изменениям порога голосовой реакции (вокализации) при раздражении корня хвоста крыс (в мА) через имплантированные подкожно биполярные металлические электроды. В качестве генератора импульсов использовали прибор ЭСЛ-1.

Оба аналгезиметрических теста проводили последовательно на каждом животном, что позволяло объективно сравнивать особенности влияния фармакологических средств при боли различного генеза $[4,17,18,20]$. Считается также, что рефлекс отдергивания хвоста в тесте tail-flick осуществляется преимущественно на уровне спинного мозга, а голосовая реакция животных на боль (вокализация) реализуется с обязательным участием структур супрасегментарного уровня $[5,6,7,8,9,10,11,12,14$, $22,21]$. Таким образом, при анализе болевой реакции можно судить о рефлекторной реакции 
на уровне спинного мозга или о реакции со стороны центральной нервной системы при анализе чувства боли.

Для регистрация артериального давления при боли, крысам предварительно наркотизированным нембуталом (40 мг/кг), вживляли хронические силиконизированные катетеры в сонную артерию и яремную вену. Катетеры были заполнены смесью гепарина и физиологического раствора в соотношении $1: 3$, Катетеры ежедневно промывали этой смесью. Свободные концы катетеров выводили под кожей на голову животного и подшивали к коже теменной части черепа. В эксперимент животных брали только через сутки после операции.

В процессе опыта регистрировали артериальное давление (АД) электроманометром ВИ6-5 МА и реакции АД при электрическом раздражении хвоста с интенсивностью, вызывавшей типичное для животных проявление боли - голосовую реакцию на боль. Одновременно регистрировали спонтанную двигательную активность и моторные реакции животных. Для этого использовали тензоплатформу, датчики которой включались в схему мостика Уинстона, подключеннову к УИП-01. Перемещения животных записывали в виде актограммы, график изменения АД записывали на чернильном самописце Н3O31-6.

Основное внимание уделялось влиянию препаратов на дыхание, тонус скелетной мускулатуры и на их миоплегический эффект реализующийся через изменение двигательной активности животного.

Для оценки изменений дыхания на грудной клетке крыс укрепляли датчик, представляющий собой резиновую трубку длиной 2-3 см, плотно заполненную мелкодисперсным угольным порошком. В процессе вдоха и выдоха изменялись размеры датчика и, следовательно, его электрическое сопротивление. Эти изменения через мостик Уинстона регистрировали на самописце в виде куполообразных кривых, по которым определяли частоту и, косвенно, глубину дыхания.

Изменения тонуса скелетной мускулатуры оценивали по времени удержания животных на горизонтальном стержне, закрепленном на расстоянии 50 см от поверхности лабораторного стола. Животное подносили к стержню и после его захвата передними лапами крысу отпускали. Оценивалось миоплегическое действие анальгетиков при этом регистрировали время удержания крыс до и после введения препаратов.

Психотропное действие фармакологических соединений определяли по их влиянию на реакцию животных, вызванную неноцицептивным «стресс-воздействием». В качестве последнего мы использовали резкий звуковой сигнал от бытового электрического звонка. Реакцию крыс на внезапный звонок оценивали в баллах: 0 - нет реакции, 1 - поворот головы в сторону звонка, 2 - переступание лапами и (или) короткая пробежка, 3 - генерализованная моторная реакция, которая проявлялась беспокойством, неупорядоченной двигательной активностью.

Изучение сократительной активности матки проводили на небеременных и беременных животных со сроками беременности близким к естественным родам.

Животным в условиях нембуталового наркоза имплантировали серебряные электроды: активный - в рог матки (1,5-2 см латеральнее от ее тела), индифферентный - под кожу живота.

O моторной активности матки судили по амплитуде биопотенциалов миометрия (в мкВ) и их частоте (за 20 секунд), которые регистрировали на 8-канальном энцефалографе ЭЭГА-21 «Энцефолан» 131-03. Общая регистрации продолжалась от 2 до 5 часов, причем в течение первого часа записывали фоновую сократительную активность матки (до введения препаратов), далее при стимуляции электрическим током, затем окситоцином и на фоне анальгегических опиатных препаратов различных по их действию на мю опиатные рецепторы. В контрольной группе животных вместо болеутоляющих средств - вводили физиологический раствор в том же, что и препараты, объеме. В качестве антагониста опиатов использовался налоксон 0,1 мг - как показатель обратимости реакций вызванных опиатами.

Статистическая обработка результатов выполнялась с использованием программного обеспечения MS Excel 2012. При статистическом анализе полученных результатов определяли среднее арифметическое (М), ошибку среднего арифметического (m). Вероятность ошибки определяли по t-критерию Стьюдента. Различия считали достоверными при $\mathrm{p}<0,05$.

\section{Результаты и обсуждение}

Исследование действия опиатных анальгетиков на крыс сроком беременности 20 дней показало, что независимо от группы препаратов действующих как агонисты мю опиатных рецепторов, агонисты-антагонистов и антагонистыагонистов - препараты, известные в фармакопии как промедол, фентанил, трамал, стадол и дипидолор вызывали однонаправленной действие при аналгезии средними дозамми в тестах tail-flick и вокализации. Латентный период реакции отдергивания удлинялся на 50-75 \%, порог вокализации повышался на 30-40\%, причем эти изменения ноцицептивных реакций развивались в интер- 
вале от 15 до 30 мин после введения препарата и были достоверными в течение 90 мин регистрации. Болеутоляющий эффект опиодов в обоих тестах имел отчетливый дозозависимый характер. Однако достоверное удлинение латентного периода отдергивания хвоста сохранялось не более 30 мин, тогда как повышение порога вокализации было более продолжительным. Налоксон $(0,1$ мг) как антагонист мю опиатных рецепторов полностью устранял аналгезию, вызванную опиатами. В тесте tail-flick экспозиция температурного воздействия не превышала 30 секунд по соображениям избежания ожогов и необратимого повреждения хвоста крыс.

Опиоиды в исследованном диапазоне аналитических доз не изменяли фоновое АД, однако оказывали «парадоксальное» влияние на прессорные реакции АД, вызванные ноцицептивным электрическим раздражением корня хвоста беременных крыс. После их введения в аналгетической дозе на фоне достоверной аналгезии в тестаx tail-flick и вокализации амплитуда ноцицептивных сдвигов АД возрастала на 25-30\%, при увеличении дозы препаратов еще значительнее увеличивалась амплитуда реакций АД, которые достигали $150 \%$ от своих контрольных значений.

Налоксон в дозе 0,1 мг устранял вегетостимулирующий эффект опиатов. Введение налоксона в дозе 1 мг на фоне опиодной аналгезии не меняло уровня АД и оно достоверно не отличалось от контроля. Систалическое АД в мм рт. ст. составляло $114,0 \pm 12,5$, при прессорных сдвигах увеличивалось на $24,3 \pm 2,4$ мм рт. ст. Различия не достигли величины достоверного уровня.

Следует подчеркнуть, что болеутоляющем действии опиатов влияние на АД у небеременных крыс и у животных со сроками беременности 20 дней было абсолютно идентичным. Таким образом, вегетативные реакции на боль, выражающиеся в повышении артериального давления, реализуются через мю-опиатные рецепторы. Экстраполируя полученные данные на болевую реакцию организма, при схватках у женщин в родах, можно сказать, что нежелательные вегетативные реакции выражающиеся в повышении артериального давления на схватку связаны с болью и должны купироваться введением опиатов, то есть для усиления опиатной защиты организма на ноцицепцию.

Психотропный эффект опиатов и их влияние на дыхание и тонус скелетной мускулатуры требует выяснения корреляции между анальгетическими и психотропным эффектами, характерными для болеутоляющих средств центрального действия. Нами проведено сопоставление психотропного действия опиоидов на реакцию жи- вотных в ответ на не болевые стресс- стимулы (резкий звонок) и как проявление общего седативного влияния - изменение состояния мышечного тонуса (время удержания на горизонтальном стержне) миоплегия.

У крыс со сроком беременности 20 дней опиоиды ослабляли реакцию животных на внезапно предъявленный звуковой сигнал и укорачивали время удержания крыс на горизонтальном стержне c 2,00 $\pm 0,01$ баллов до $1,75 \pm 0,08$ (достоверно при $\mathrm{P}<0,05$ по сравнению с контролем). Частота дыхания достоверно уменьшалась с $80 \pm 2$ до $60 \pm 4$ (достоверно при $\mathrm{P}<0,05$ по сравнению с контролем). У небеременных животных в аналгетических дозах опиоиды практически не изменяли показатели, характеризующие психотропное и седативное действие препаратов. Эффекты опиоидных препаратов изчезают при введении налоксона, что позволяет сделать вывод о реализации эффекта через опиатные рецепторы.

Важным проявлением фармакологического действия центральных аналгетиков является их влияние на дыхание, поскольку общеизвестно, что опиатоподобные средства в диапазоне аналитических доз отчетливо снижают частоту дыхания и нарушают его глубину. Наши скрининговые исследования подтвердили, что опиаты в больших дозах достоверно снижают частоту дыхательных движений крыс (с 80,4 $\pm 5,3$ до 62,5 $\pm 4,2$ ) и уменьшают их глубину. При аналгезии средними и малыми дозами на фоне модели родов у беременных крыс, частота дыхания практически не изменялась, дыхание оставалась ритмичным и глубоким.

В опытах на контрольных группах животных было установлено, что психотропный эффект препаратов и их влияние на дыхание полностью небеременных у интактных и беременных крыс.

Нами показано, что опиаты по-разному влияют на частоту и амплитуду маточных сокращений беременных и небеременных крыс, что так же зависит от дозы препарата. Этот факт косвенно подтверждает участие опиатной антиноцецептивной системы в родах. По-видимому, опиатная защита в родах от боли формируется в процессе эволюции и генетически детерменирована. Это позволяет предположить, что аномалии родовой деятельности человека определяются генетическим несовершенством опиодэргической части антиноцицептивной системы.

У беременных животных опиаты в минимальных дозах не влияли достоверно на оба показателя маточной активности, хотя прослеживалась тенденция к увеличению амплитуды маточных сокращений, при этом базальный тонус незначительно снижался. При терапевтических анальге- 
тических дозах снижалась амплитуда маточных сокращений до $87,0 \pm 1,3 \%$ и увеличивалась частота до $110 \pm 1,6 \%$, причем уже через 15 минут от введения препарата. Через 30 минут амплитуда снижаласьь до $81,0 \pm 1,4 \%$, а частота увеличивлась до117,0 2,0\% (достоверно при $\mathrm{P}<0,05$ при сравнении с контролем). При увеличении дозы препарата, к 30 минуте регистрации произошло более значительное снижение амплитуды при некотором увеличении частоты маточных сокращений достоверно $(75,5 \pm 1,4 \%$ и $115,5 \pm 1,1 \%$ соответственно). Применение опиатных анальгетиков у интактных крыс, как и физиологического раствора не изменяло частоту и амплитуду биопотенциалов миометрия.

Антагонисты кальциевых каналов и налоксон уменьшали частоту и амплитуду сокращений и снимали окситоцин индуцированные сокращения беременной матки. Этот факт говорит об осторожном применении антагонистов кальциевых каналов в сочетании с опиатами при обезболивании родов и регуляции родовой деятельности (лечения дискоординации и других аномалий родовой деятельности у женщин).

Опиаты в зависимости от дозы по-разному влияли на частоту и амплитуду маточных сокращений у небеременных и беременных крыс. При увеличении дозы опиатов уже к 30 мин. после введения происходило увеличение а затем дозозависимое уменьшение, амплитуды сокращений миометрия. Описанный эффект был характерен для опиоидов после введения крысам со сроками беременности 20 дней. В то же время у интактных крыс-самок опиоиды не вызывали достоверных изменений частоты и амплитуды биопотенциалов миометрия.

Проведенные эксперименты показали, что опиоиды в средних и высоких дозах дозах вызывают равно выраженную отчетливую аналгезию. Торможение болевых реакций в алгезиметрических тестах, характеризующих супра- и сегментарные механизмы боли, подтвердило центральный механизм болеутоляющего действия.

Важно также, что для опиоидов не выявлен негативный эффект подавления дыхательного центра в модели аналгезии родов малыми дозами, но он проявляется при использовании опиодов в высоких альгетических дозах.

Для оценки перспектив применения опиоидов для обезболивания родов важными явились данные, о их влиянии на активность миометрия у беременных животных. Было установлено, что опиоиды в малых анальгетических дозах повышают амплитуду и практически не изменяет частоту сокращений матки. Такое благоприятное «маточное» действие опиоидов при модели обе- зболивания родов малыми субанальгетическими дозами выгодно отличает опиоидную аналгезию средними дозами, при которых присуще некоторое снижение амплитуды маточных сокращений и, вероятно, как компенсация этому — увеличение частоты схваток. Нами показано, что аналогичное действие характерно для блокаторов кальциевых каналов в отношении амплитуды маточных сокращений. Опиоиды синергично усиливают это влияние снижая частоту окситоцин модулируемых схваток при аналгезии опиоидами. При высоких дозах опиоидов наблюдается ослабление родовой деятельности по амплитуде и частоте коррегируемое налаксоном.

Таким образом, экспериментальные данные позволяют заключить, что опиоиды обладают центральным болеутоляющим эффектом, причем в анальгетических дозах не вызывают изменений АД, дыхания и не нарушают сократительную активность беременной матки. На основании экспериментов можно предположить, что и в условиях реальной акушерской клиники опиоиды по сумме свойств дают преимущества перед регионарной анестезией, воздействуя на механизмы сократительной активности миометрия через ионные каналы, что при умелом сочетании с препаратами - блокаторами кальциевых каналов и налаксоном могут являться средствами, дозозависимо регулирующими сократительную функцию матки в родах.

Несмотря на частое использование опиоидных анальгетиков для обезболивания родов, влияние их на сократительную способность матки изучено недостаточно. В то же время можно полагать, что опиоидэргическая антиноцицептивная система должна оказывать влияние на регуляцию родовой деятельности $[12,15,16,19]$. С одной стороны, комплекс реакций на боль облегчает реализацию эффективного раскрытия шейки матки и создания правильного ритма сократительной деятельности матки человека приводящий, в конечном результате, к успешным родам $[1,3,13]$. С другой стороны, неполноценность эндогенной опиатной системы женщины может лежать в основе развития аномалий родовой деятельности, если предположить, что чрезмерное болевое ощущение нарушает механизмы нормальной сократительной деятельности матки $[3,14]$.

Статья представлена М. А. Петросяном, ФГБНУ «НИИ АГИР им. Д. О. ОтТа»,

Санкт-Петербург

\section{Литература}

1. Абрамченко В.В., Киселев А.Г., Орлова О.О., Абдуллаев Д.Н. Ведение беременности и родов высокого риска. СПб.; 1995. 
2. Абрамченко В.В., Киселев А. Г., Аль-Хури Амат Аль-Карим Али.Обезболивание родов. СПб.; 1996.

3. Айламазян Э. К., Игнатов Ю. Д., Зайцев А. А., Киселев А. Г., Аль-Хури Амат Обезболивание родов трамалом. Материалы симпозиума «Лечение боли аналгетиком трамалом». Новгород; 1995: 9-10.

4. Богданов Е.Г., Зайцев А.А., Цуринов А.Д., Удовиченко Н.А. Компьютерная система для синхронного поэтапного анализа показателей биоэлектрической активности и системной гемодинамики. Бюллетень экспериментальной биологии. 1987; 103: 575-7.

5. Вислобоков А.И. и др. Мембранные механизмы действия на нервные клетки анестетиков и анальгетиеков и противоаритмических средств. Медицинский академический журнал. 2001; 1 (1): 25-33.

6. Зайцев А.А. Петряевская Н.В. Влияние клофрелина на анальгетический эфрфект морфина. Фармакология и токсикология. 1986; 4: 40-4.

7. Зайцев А.А. Экспериментально-клиническое обоснование нового направления медикаментозной анальгезии и регуляции гемодинамики при боли. Авторефр. дис... д-ра. мед. наук. Л.; 1988.

8. Зайцев А.А., Игнатов Ю.Д., Харьковский А.О. Влияние наркотических анальгетиков на ноцицептивные реакции висцеральной и соматической природы. Экспериментальная и клиническая фрармакология. 1992; 5: 84-7.

9. Зайцев А.А., Карпов О.И Опиатные анальгетики: особенности и применение. Терра медика. 1997; 3: 32-5.

10. Игнатов Ю.Д., Савоськин А.Л., Вислобоков А.И., Зайцев А. А. Фармакология опиатных и неопиатных анальгетиков центрального действия. Тез. докл. Всеросс. науч. конфр. «Актуальные проблемы экспериментальной и клинической фрармакологии». СПб.; 1999: 74.

11. Игнатов Ю.Д., Зайцев А. А., Богданов Е. Г. Роль опиатных пептидов в регуляции ноцицептивных гемодинамических реакций. Тез. докл. симп. «Физиология пептидов». Л.; 1988: 80-1.

12. Игнатов Ю.Д., Зайцев А.А. Современные аспекты терапии боли: опиаты. Качественная клиническая практика. 2001; 2: 2-13.

13. Киселев А.Г. Зайцев А. А. Методические рекомендации для врачей акушеров-гинекологов по применению трамадола (гидрохлорида трамала) для обезболивания родов. СПб.; 1998

14. Киселев А. Г. Зайцев, А. А., Смирнов А. А., Куличкин Ю. В., КолодницкийТ.Е. Особенности опиоидной анальгезии в родах. Тез.докл. 4-й межд. специализир. выставки « Аптека Санкт-Петербурга-99». СПб.; 1999: 69.

15. Киселев А.Г., Зайцев А.А., Куличкин Ю.В., Абрамченко В.В., К Колодницкий Т.Е. Эффрективность опиоидной анестезии в родах. Тез. докл. Пленума Российской ассоциации акушеров-гинекологов «Инфекции в акушерстве, гинекологии и перинаталогии». Саратов; 1999

16. Киселев А.Г., Коростелев Ю.М., Первак В.А., Широков Д. М. Модели регуляции опиатными анальгетиками сократительной деятельности матки человека в эксперимен- те на изолированных полосках миометрия. Ж. акушерства и женских болезней. 2007; T. LVII (спецвып.): 22-3.

17. Коростелев Ю.М., Киселев А.Г., Первак В.А., Широков Д.М. Современный взгляд на обезболивание родов. Медлайн-экспресс. 2006; 5-6 (188): 57-62.

18. Коростелев Ю.М., Киселев А.Г., Первак В.А., Широков Д. М. Обезболивание родов. Signatura. 2007; 2: 11-6.

19. Прощаев К.И., Ильницки А.Н., Князькин И.В., Кветной И. М. Боль. Молекулярная нейроиммуноэндокринология и клиническая патофизиология. СПб.: ДЕАН; 2006.

20. Bradford H.F, Crowder J.M., White E.J. Inhibitori actions of opioid compounds on calcium fluxes and neurotransmitter releas from mammalan cerebral cortcal slices. Brit. Sains Pharvacol. 1986; 88: 87-93.

21. Kiselev A.G., Gordeev V.I., Kulitchkin Y.V., Shadrin. A.P. Opioid analgesia in labour. Environment and Human health: The Works of International Ecologic Forum, June 29 - July 2, 2003, St.Petersburg Russia. SPb.: SpecLit; 2003: 384-5.

22. Kiselev A. G., Lopatin D.A., Kulitchkin Y.V., Kolodnitsky T.E. Probability labour activity after opioid analgesia in the preliminar period. Journal of obctetrics and women's diseases. 1999; XLVIII (1): 79.

23. Kiselev A. G., Zaitcev A.A, Kulitchkin Y. V., Kolodnitsky T. E. Efficiency of opioid analgesis in labour. Journal of obctetrics and women's diseases. 1999; XLVIII (1): 80.

\section{References}

1. Abramchenko V.V., Kiselev A.G., Orlova O.O., Abdullaev D. N. Vedenie beremennosti i rodov vysokogo riska [Prenatal care and delivery of high-risk]. SPb.; 1995. (in Russian).

2. Abramchenko V. V., Kiselev A. G., Al'-Huri Amat Al'-Karim Ali. Obezbolivanie rodov [Anesthesia delivery]. SPb.; 1996. (in Russian).

3. Ajlamazjan Je.K., Ignatov Ju.D., Zajcev A.A., Kiselev A. G., Al'-Huri Amat Obezbolivanie rodov tramalom [Anesthesia delivery tramalom]. Materialy simpoziuma «Lechenie boli analgetikom tramalom». Novgorod; 1995: 9-10. (in Russian).

4. Bogdanov E.G., Zajcev A.A., Curinov A.D., Udovichenko N. A. Komp'juternaja sistema dlja sinhronnogo pojetapnogo analiza pokazatelej biojelektricheskoj aktivnosti i sistemnoj gemodinamiki [Computer system for simultaneous analysis of the phase indicators bioelectrical activity and systemic hemodynamics]. Bjulleten' jeksperimental'noj biologii. 1987; 103: 575-7. (in Russian).

5. Vislobokov A.l. i dr. Membrannye mehanizmy dejstvija na nervnye kletki anestetikov i anal'getiekov i protivoaritmicheskih sredstv [Membrane mechanisms of action of anesthetics on nerve cells and analgetiekov and antiarrhythmics]. Medicinskij akademicheskij zhurnal.2001;1 (1): 25-33. (in Russian).

6. Zajcev A.A. Petrjaevskaja N. V. Vlijanie klofelina na anal'geticheskij jeffekt morfina [Effect of clonidine on the analgesic effect of morphine]. Farmakologija i toksikologija. 1986; 4: 40-4. (in Russian).

7. Zajcev A.A. Jeksperimental'no-klinicheskoe obosnovanie novogo napravlenija medikamentoznoj anal'gezii i reguljacii gemodinamiki pri boli [Experimental and clinical study of a new 
direction of medical analgesia and hemodynamic regulation at pains]. Avtoref. dis... d-ra. med. nauk. L.; 1988. (in Russian).

8. Zajcev A.A., Ignatov Ju.D., Har'kovskij A. O. Vlijanie narkoticheskih anal'getikov na nociceptivnye reakcii visceral'noj somaticheskoj prirody [The influence of narcotic analgesics for nociceptive responses of visceral and somatic nature]. Jeksperimental'naja i klinicheskaja farmakologija. 1992; 5: 84-7. (in Russian).

9. Zajcev A.A., Karpov O.I Opiatnye anal'getiki: osobennosti i primenenie [Opioid analgesics: Features and applications] Terra medika. 1997; 3: 32-5. (in Russian)

10. Ignatov Ju.D., Savos'kin A.L., Vislobokov A.I., Zajcev A.A. Farmakologija opiatnyh i neopiatnyh anal'getikov central'nogo dejstvija [Pharmacology and opiate analgesics central action neopiatnyh]. Tez. dokl. Vseross. nauch. konf. "Aktual'nye problemy jeksperimental'noj i klinicheskoj farmakologii". SPb.; 1999: 74. (in Russian).

11. Ignatov Ju.D., Zajcev A.A., Bogdanov E.G. Rol' opiatnyh peptidov $\vee$ reguljacii nociceptivnyh gemodinamicheskih reakcij [The role of opioid peptides in the regulation of nociceptive hemodynamic responses]. Tez. dokl. simp. "Fiziologija peptidov". L.;1988: 80-1.

12. Ignatov Ju.D., Zajcev A.A. Sovremennye aspekty terapii boli: opiaty [Modern aspects of treatment of pain: opiates]. Kachestvennaja klinicheskaja praktika. 2001; № 2: 2-13. (in Russian)

13. Kiselev A. G. Zajcev A. A. Metodicheskie rekomendacii dlja vrachej akusherov-ginekologov po primeneniju tramadola (gidrohlorida tramala) dlja obezbolivanija rodov [Guidelines for obstetricians and gynecologists on the application of tramadol (Tramal hydrochloride) for pain relief in labor]. SPb.; 1998. (in Russian).

14. Kiselev A. G. Zajcev, A.A., Smirnov A.A., Kulichkin Ju.V., Kolodnickij T.E. Osobennosti opiodnoj anal'gezii $\vee$ rodah [Features of opioid analgesia in labor]. Tez.dokl. 4-j mezhd. specializir. vystavki «Apteka Sankt-Peterburga-99». SPb.; 1999: 69. (in Russian).

15. Kiselev A. G., Zajcev A.A., Kulichkin Ju.V., Abramchenko V.V., Kolodnickij T.E. Jeffektivnost' opiodnoj anestezii $\vee$ rodah [Effectiveness of opioid analgesia in labor]. Tez. dokl. Plenuma Rossijskoj associacii akusherov-ginekologov «Infekcii v akusherstve, ginekologii i perinatalogii». Saratov; 1999. (in Russian)

16. Kiselev A.G., Korostelev Ju.M., Pervak V.A., Shirokov D. M. Modeli reguljacii opiatnymi anal'getikami sokratitel'noj dejatel'nosti matki cheloveka $v$ jeksperimente na izolirovannyh poloskah miometrija [Models of regulation of opiate analgesics uterine activity in human experiments on isolated strips of myometrium]. Zhurnal akusherstva i zhenskih boleznej. 2007; T. LVII (specvyp.): 22-3. (in Russian).

17. Korostelev Ju.M., Kiselev A.G., Pervak V.A., Shirokov D.M. Sovremennyj vzgljad na obezbolivanie rodov [The modern view on labor pain relief]. Medlajn-jekspress. 2006; 5-6 (188): 57-62. (in Russian).

18. Korostelev Ju.M., Kiselev A.G., Pervak V.A., Shirokov D. M. Obezbolivanie rodov [Labor pain relief.]. Signatura. 2007; 2: 11-6. (in Russian).

19. Proshhaev K.I., II'nicki A. N., Knjaz'kin I.V., Kvetnoj I. M. Bol'. Molekuljarnaja nejroimmunojendokrinologija i klinicheskaja patofiziologija [Pain. Molecular and clinical pathophysiology neyroimmunoendokrinology]. SPb.: DEAN; 2006. (in Russian).

20. Bradford H.F, Crowder J.M., White E.J. Inhibitori actions of opioid compounds on calcium fluxes and neurotransmitter releas from mammalan cerebral cortcal slices. Brit. Sains Pharvacol. 1986; 88: 87-93.

21. Kiselev A. G., Gordeev V.I., Kulitchkin Y.V., Shadrin. A.P. Opioid analgesia in labour. Environment and Human health: The Works of International Ecologic Forum, June 29 July 2, 2003, St. Petersburg Russia. SPb.: SpecLit; 2003: 384-5.

22. Kiselev A. G., Lopatin D. A., Kulitchkin Y.V., Kolodnitsky T.E. Probability labour activity after opioid analgesia in the preliminar period. Journal of obctetrics and women's diseases. 1999; XLVIII (1): 79.

23. Kiselev A. G., Zaitcev A.A, Kulitchkin Y. V., Kolodnitsky T. E. Efficiency of opioid analgesis in labour. Journal of obctetrics and women's diseases. 1999; XLVIII (1): 80

\section{- Адреса авторов для переписки}

Киселев Андрей Геннадьевич - к. м. н., доцент, врач анестезиологреаниматолог. ФГБНУ «НИИ АГиР им. Д. О. Отта». 199034, Россия, Санкт-Петербург, Менделеевская линия, д. 3.

E-mail: iagmail@ott.ru.

Зайцев Александр Афанасьевич - д. м. н., профессор. НИИ фармакологии им Вальдмана. 197022, Россия, Санкт-Петербург, ул. Льва Толстого, д. 6/8. E-mail: bhsm@mail.ru.
Kiselev Andrey Gennadyevich — PhD, Assosiate Professor, anesthesiologist and intensive care doctor. D. O. Ott Research Institute of Obstetrics and Gynecology, RAMS. 199034, St. Petersburg, Mendeleyevskaya Line, 3, Russia. E-mail: iagmail@ott.ru.

Zaitsev Alexander Afanasievich — Professor, Doctor. M.Sc. Waldman Research Institute of Pharmacology. 197022, St. Petersburg, Lev Tolstoy St., 6/8, Russia. E-mail: bhsm@mail.ru. 